\title{
Centro de Atenção Psicossocial, o cuidado em saúde mental no Distrito Federal, Brasil
}

\section{Psychosocial Care Center, the mental health care in the Federal District, Brazil}

\section{Red de Atención Psicosocial, el cuidado en salud mental en Distrito Federal, Brasil}

Maria da Glória Lima ${ }^{1}$

Maria Aparecida Gussi ${ }^{2}$

Antonia Regina Ferreira Furegato ${ }^{3}$

RESUMO: Este trabalho objetivou identificar práticas de cuidado realizadas pelos profissionais de saúde mental dos Centros de Atenção Psicossocial (CAPS), na Rede de Atenção Psicossocial do Distrito Federal, tendo por base o modelo psicossocial, preconizado pelas diretrizes políticas de saúde mental. Estudo exploratório, com dados quanti-qualitativos, mediante a realização de entrevistas semiestruturadas, junto a 126 profissionais de saúde de nível superior e médio, em nove CAPS para atendimento de usuários com transtornos mentais e com uso de álcool e outras drogas, realizadas no período maio de 2011 a julho de 2012, após aprovação do Comitê de Ética em Pesquisa da Secretaria de Saúde do DF, parecer n0081/2010. Os resultados revelam que os profissionais, em sua maioria, são mulheres e adultos jovens, com pouco preparo e experiência na saúde mental, e que, todavia reconhecem o CAPS como dispositivo potente para o modelo psicossocial. Entretanto, referem encontrar desafios relativos à formação básica dos profissionais, preparo especifico e interesse em trabalhar na saúde mental. Referem ainda limites institucionais (inadequadas condições de trabalho, insuficiência numérica e baixa articulação dos serviços RAPS) e falta de priorização da saúde mental, na agenda política local. Conclui-se que os profissionais das equipes de saúde mental que atuam no CAPS têm buscado, na organização do trabalho, superar os desafios, buscando o aprendizado de saberes e práticas de saúde para novas formas de produzir

1 Enfermeira, Professora Associada do Departamento de Enfermagem, Universidade de Brasília.

2 Enfermeira, Professora Adjunta do Departamento de Enfermagem, Universidade de Brasília

3 Enfermeira, Professora Titular, Aposentada e Colaboradora Sênior da Escola de Enfermagem de Ribeirão Preto, Universidade de São Paulo 
o cuidado em saúde mental mais convergente com o modelo psicossocial, preconizado pelas diretrizes políticas nacionais e locais de saúde mental.

Palavras chave: Saúde mental, Serviços de Saúde Mental, Centros de Atenção Psicossocial, Trabalho, Práticas de cuidado em saúde

\begin{abstract}
This study aimed to identify the care practices performed by professionals of the Psychosocial Care Centers (CAPS), at of the Care Network Psychosocial model of the Federal District, having the psychosocial model advocated by the political mental health guidelines as foundation. Exploratory study, with quanti-qualitative data, through semi-structured interviews with 126 health professional with higher and high school education levels in nine CAPS for users with mental disorders and alcohol abuse and other drugs, performed from May 2011 to July 2012, after approval by the Research Ethics Committee of the Secretariat of Health of the Federal District, technical advice number 0081/2010. The results show that professionals are mostly women and young adults, with little training and experience in mental health, and who, however, recognize the CAPS as a powerful device for the psychosocial model. However, they refer to finding challenges related to training, preparation and interest in working in mental health. They also refer to the institutional limits (inadequate working conditions, numerical insufficiency and low articulation of RAPS); and the lack of prioritizing mental health in the local political agenda. It is concluded that professionals of the mental health teams that work in the CAPS have sought, in the organization of work, overcome the challenges, seeking the learning of health knowledge and practices for new ways of producing the mental health care more convergent with the psychosocial model, as recommended by the national and local guidelines of mental health policies.
\end{abstract}

Key words: Mental health, Mental Health Services, Psychosocial Care Centers, Work, Health Care Practices

RESUMEN: Este trabajo tuvo por objetivo caracterizar las prácticas de cuidado realizadas por los profesionales de salud mental de los Centros de Atención Psicosocial - CAPS, pertenecientes a la Red de Atención Psicosocial del Distrito Federal, en cuanto al modelo psicosocial preconizado por las directrices políticas de salud mental. Estudio exploratorio, con datos cuantitativos y cualitativos, mediante la realización de entrevistas semiestructuradas junto a 126 profesionales de salud de nivel superior y medio en nueve CAPS para atención de usuarios con trastornos mentales y/o con uso de alcohol y otras drogas, realizadas en el período de mayo de 2011 hasta julio de 2012, previa aprobación del Comité de Ética en Investigación de la Secretaría de Salud del DF, dictamen $n^{\circ} 0081 / 2010$. Los resultados revelan que los profesionales, en su mayoría, son mujeres y adultos jóvenes, con poca preparación y experiencia en salud mental. Sin embargo, reconocen el CAPS como dispositivo potente para el modelo psicosocial, pero refieren encontrar desafíos relativos a los profesionales en cuanto a la formación, la preparación y el interés en trabajar en la salud mental, y aún a los límites institucionales, como inadecuadas condiciones de trabajo, insuficiencia numérica y baja articulación de los servicios RAPS; y la no priorización de la salud 
mental en la agenda política local. Se concluye que los profesionales de los equipos de salud mental que actúan en los CAPS han buscado en la organización del trabajo superar los desafíos, buscando el aprendizaje de saberes y prácticas de salud para nuevas formas de producir el cuidado en salud mental más convergente con el modelo psicosocial, preconizado por las directrices políticas nacionales y locales de salud mental.

Palabras claves: Salud Mental, Servicios de salud mental, Red de Atención Psicosocial, Trabajo, Prácticas de cuidado de la salud

\section{INTRODUÇÃO}

O paradigma psicossocial se configura como possibilidade de produzir novas formas de relação social, com a produção de novos saberes e práticas na forma de conceber o fenômeno da loucura e a doença mental, contrapondo-se, positivamente, ao modo asilar que se instituiu hegemonicamente nas instituições psiquiátricas, com ênfase na medicalização, no isolamento e na segregação da pessoa que passa pela experiência do sofrimento psíquico $^{1}$.

O paradigma psicossocial, também conhecido como desinstitucionalização ${ }^{2}$, com ênfase na cidadania e na liberdade do portador de transtorno mental, ganhou força, a partir do movimento da Reforma Psiquiátrica e passou a orientar o arcabouço teórico-metodológico e ideológico na formulação das novas diretrizes políticas de atenção à saúde mental no mundo e no Brasil, principalmente a partir dos anos 90 .

A desinstitucionalização é vista como um "trabalho prático de transformação", mais especificamente, os modos como as pessoas são tratadas para transformar o seu sofrimento e as possibilidades de reprodução social na vida concreta ${ }^{3}$.

\footnotetext{
"este trabalho de desinstitucionalização voltado para reconstruir as pessoas como atores sociais, para impedir-lhes o sufocamento sob o papel, o comportamento, a identidade estereotipada e introjetada que é a máscara que se sobrepõe à dos doentes. Que tratar signifique ocupar-se aqui e agora para que se transformem os modos de viver e sentir o sofrimento do paciente e que ao mesmo tempo se transforme a sua vida concreta cotidiana ${ }^{4}$.
}

O Relatório da Organização Mundial da Saúde-OMS, de 2001, recomenda aos países maior empenho e responsabilização na elaboração e implementação de políticas públicas de saúde mental, de maneira a avançar na "integração do tratamento e dos serviços de saúde mental no sistema geral de saúde, e especialmente nos cuidados primários", com a definição de prioridades das necessidades de saúde mental, condições, serviços, tratamentos e estratégias de promoção, prevenção e reabilitação em saúde mental, uma vez que essa população com problemas de saúde historicamente foi negligenciada e excluída do acesso ao cuidado integral em saúde.

No Brasil, a partir da aprovação da Lei 10.216/20016 que trata dos direitos e da proteção dos 
usuários da saúde mental, o Estado assumiu papel incisivo na reestruturação da atenção psiquiátrica, favorecendo o incremento de normativas para a gradativa efetivação da reestruturação do modelo assistencial em saúde mental, com a criação de novos serviços comunitários e ambulatoriais.

Nesse arcabouço normativo jurídico com vistas à desinstitucionalização destacam-se: a Portaria No 336/GM ${ }^{7}$, de 19 de fevereiro de 2002, a criação do dispositivo dos Centros de Atenção Psicossocial - CAPS, serviços comunitários especializados e territorializados para tratamento de pessoas com transtornos mentais e com problemas relacionados ao uso de álcool e outras drogas, para população adulta e infanto juvenil, com a responsabilidade de ordenar a organização da atenção à saúde mental. Para a reabilitação e reintegração de pessoas com transtorno mental, egressas de hospitais psiquiátricos ou de custódia, ou para as que se caracterize situação de grave dependência institucional, foram criadas a Portaria de $n^{0} 106 / 2000^{8}$, que dispõe sobre as Residências Terapêuticas e a Lei Federal n ${ }^{\circ} 10.708 / 2003^{9}$ que institui o Programa De Volta para Casa, na concessão do auxílio-reabilitação psicossocial para a atenção e o Decreto $n^{0} 7.508 / 2011^{10}$, com a finalidade de organizar e integrar as ações e serviços de saúde em regiões de saúde em níveis de complexidade crescente, para assegurar à integralidade da assistência a saúde, conformando as redes de atenção à saúde - RAS, incluso a atenção psicossocial. Portaria $n^{0} 3.088 / 2011^{11}$ que regulamenta a Rede de Atenção Psicossocial.

A reestruturação da Rede de Atenção Psicossocial - RAPS ${ }^{11}$ reafirma as diretrizes de proteção e dos direitos das pessoas com sofrimento ou transtorno mental e com necessidades decorrentes do uso de crack, álcool e outras drogas, tratamento em serviços comunitários de saúde mental. E entre os eixos estratégicos estão a ampliação e a qualificação do acesso à rede de atenção integral à saúde mental, a articulação e a integração de ações interssetoriais para reinserção social e reabilitação, mediante ações de prevenção e de redução de danos, de forma a garantir o acesso e a articulação e integração dos pontos de atenção das redes de saúde no território, qualificando o cuidado por meio do acolhimento, do acompanhamento contínuo e da atenção às urgências.

Assim, a RAPS para reestruturação da atenção à saúde mental compreende estrategicamente serviços e equipamentos variados como: os Centros de Atenção Psicossocial (CAPS); atendimento na atenção básica; serviços ambulatoriais; serviços residenciais terapêuticos (SRT); Centros de Convivência e Cultura, Unidade de Acolhimento (UAs); e, leitos de atenção integral (em Hospitais Gerais, nos CAPS Modalidade III). O modelo psicossocial para atenção à saúde mental recomenda que os serviços, além de serem situados perto do domicílio, disponham de uma rede diversa de equipamentos de saúde que possam atender os diferentes momentos do adoecimento, com integração interssetorial, ações de saúde que tenham por base as necessidades de saúde dos usuários da psiquiatria e da saúde mental ${ }^{11}$.

No entanto, esta reestruturação psicossocial esbarra em limites na garantia do acesso aos equipamentos e atendimento das necessidades de usuários e familiares pois verifica-se uma rede insuficiente, embora com avanços significativos para potencializar os princípios da reforma 
psiquiátrica $^{12}$. No sentido de ampliar a capacidade de cobertura para os problemas de saúde e, em específico, para os problemas de saúde mental, que às vezes carece de uma rede de serviços da RAPS constituídas, como também, de profissionais qualificados e especialistas na área, é necessário o investimento específico pelo poder público.

Cabe ressaltar a importância dos profissionais de saúde para produzir a desinstitucionalização, tanto no exercício do seu papel terapêutico como gerencial, influenciando os usuários da saúde mental e toda a sua rede de relações ${ }^{3}$.

“A relação terapêutica torna-se uma fonte de poder que é utilizada também para chamar a responsabilidade e ao poder os outros atores institucionais, próximos ou não, os administradores locais responsáveis pela saúde mental, os técnicos das estruturas locais responsáveis, os políticos, etc”3.

Daí o interesse deste estudo ao buscar identificar a conformação das práticas de saúde, realizadas pelos profissionais dos Centros de Atenção Psicossocial, de forma a oferecer subsídios para o aprimoramento das políticas e das práticas de saúde, bem como da capacitação profissional e organização do trabalho em saúde mental e psiquiatria.

Neste sentido, buscou-se explorar a organização do trabalho realizado pelos profissionais de nível superior e médio que atuam nos Centros de Atenção Psicossocial, no atendimento à população adulta com transtornos mentais e/ou com problemas relacionados ao uso de álcool e outras drogas, da rede pública do Distrito Federal, cotejada com as políticas nacionais de saúde mental no Brasil.

\section{MÉTODOS}

Trata-se de estudo descritivo e exploratório, com dados quantitativos e qualitativos com vistas à caracterização do perfil socioprofissional dos sujeitos participantes e das suas práticas de saúde mental, desenvolvidas nos serviços CAPS, do Distrito Federal.

A combinação da pesquisa descritiva, aliada com a exploratória tem por objetivo tanto descrever as características de determinada população ou fenômeno, como proporcionar uma nova visão geral do problema ${ }^{13}$.

Este estudo abarcou um recorte dos equipamentos investigado da RAPS, de um subconjunto dos nove CAPS existentes a época do estudo, da rede de atenção à saúde mental da Secretaria de Estado de Saúde do Distrito Federal - SES/DF, voltados para o atendimento da população adulta. Do universo estudado, três CAPS são na modalidade II, para o atendimento de pessoas com transtorno mental (tm), localizados nas cidades administrativas Paranoá, Taguatinga e Samambaia e seis CAPS para atendimento de usuários com problemas do uso de álcool e outras drogas, sendo cinco na modalidade II, distribuídos nas cidades de Ceilândia, Guará, Itapoã e Santa Maria e Sobradinho, um na modalidade III, CAPSad Rodoviária, localizado em na área central de Brasília. 
Compuseram a amostra deste estudo 126 profissionais de saúde, dentre os quais, 92 tinham nível superior de formação e 34 de nível médio, inclusos dois técnicos administrativos e um agente de ação social que informaram realizar atividades assistenciais. Foram incluídos na amostra profissionais de saúde que estavam em exercício e pertencentes ao quadro de profissionais, lotados em atividade assistencial junto à clientela atendida nesses serviços (usuários e familiares), independentemente do tempo de atuação nos CAPS.

O levantamento de dados foi realizado no período de maio de 2011 a julho de 2012, e envolveu entrevistas com uso de roteiro semiestruturado, validado no polo coordenador responsável pela pesquisa multicêntrica. Os profissionais foram contatados pessoalmente e as entrevistas agendadas previamente e realizadas no próprio local. Esclarecidas as possíveis dúvidas, os participantes foram solicitados a assinar o Termo de Consentimento Livre e Esclarecido, e, também, o aceite para gravação em áudio.

Antes do início da coleta de dados nos serviços foi feito um alinhamento dos instrumentos com a equipe de pesquisa e, a entrada no campo precedeu de uma observação simples, que resultou em uma breve descrição dos serviços quanto à sua organização, quantitativo de trabalhadores e categoria profissional e às modalidades das práticas desenvolvidas no local.

Para a análise dados quantitativos utilizou-se uma método descritivo, por meio de estatística simples e, os dados qualitativos foram objeto de tratamento analítico visando à contextualização e reflexão dos sentidos atribuídos pelos profissionais nas descrições sobre a organização dos serviços e das práticas realizadas, bem como à sua adequação das políticas desenvolvidas nos CAPS, no conjunto dos resultados local e nacional, com base na literatura sobre o tema.

Aspectos éticos: Este estudo faz parte de um projeto de pesquisa de caráter multicêntrico, intitulado "Papéis e funções dos Profissionais de Serviços e Políticas de saúde mental - Projeto OPS/2003", sob a coordenação da Professora Antônia Regina Ferreira Furegato, da Escola de Enfermagem de Ribeirão Preto/ Universidade de São Paulo, com aprovação do Comitê de Ética do Hospital das Clínicas da Faculdade de Medicina de Ribeirão Preto - USP (Processo HCRP $\left.n^{0} 13282 / 2005\right)^{14}$. A pesquisa aqui apresentada também teve aprovação do Comitê de Ética em Pesquisa da FEPECS, da Secretaria de Saúde do Distrito Federal - SES/DF, parecer $n^{\circ}$ 0081/2010, replicado no Distrito Federal, com apoio financeiro da FAPDF, Edital PPSUS 013/2010. O projeto e seu protocolo de aprovação do CEP foram apresentados à Coordenação de Saúde Mental, Secretaria de Saúde e Gerências dos serviços CAPS da rede de saúde mental do DF. Os entrevistados foram convidados a participar da pesquisa, receberam as orientações e esclarecimento de dúvidas referentes ao estudo, assegurados o sigilo e seu anonimato, segundo a Resolução do Conselho Nacional de Saúde no 196/1996, vigente à época. 


\section{RESULTADOS E DISCUSSÃO}

\section{1 - A Rede de Atenção Psicossocial no DF}

A criação e expansão de uma rede substitutiva no Distrito Federal, de base territorial e descentralizada, tem se dado de forma mais tardia e lenta, conforme preconizado pela Política Nacional de Saúde Mental, principalmente de CAPS e de serviço residencial terapêutico. Este último inexistente até o momento, sendo que no Plano Diretor de Saúde Mental no DF, 2011 a $2015^{15}$ foi diagnosticada a necessidade de expansão da rede, com a projeção de 46 CAPS e de 11 residências terapêuticas até 2016. Cabe destacar que o primeiro CAPS foi inaugurado apenas em 2004, para atendimento de pessoas com problemas de álcool e drogas.

A referência para internações em situações de crise e emergência é feita prioritariamente no Hospital São Vicente de Paulo - HSVP, unidade especializada tradicional, localizado em Taguatinga, o qual recebe muitas críticas por eternizar o modelo psiquiátrico asilar para intervenção em crise ${ }^{16,17}$. A referência para comorbidade clínica ocorre na Unidade de Psiquiatria - UP, é uma instalação predial em área independente no Hospital de Base - HBDF, em Brasília. Há referência de leitos em hospitais gerais para o atendimento na área de saúde mental, mas os profissionais dos serviços CAPS referem dificuldades na sua utilização, pois os usuários geralmente passam por uma avaliação e são logo encaminhados para a referência hospitalar especializada HSVP ou UP/HBDF. A referência hospitalar para internação da população infanto-juvenil é o Hospital Materno Infantil de Brasília (HMIB) ou a UP/HBDF.

A rede de serviços especializados na modalidade CAPS está constituída por 18 serviços. Para atendimento de pessoas adultas, sete CAPSad são para referência do uso de álcool e outras drogas, onde cinco são na modalidade II, localizados em Itapoã, Guará, Santa Maria, Sobradinho, e três na modalidade III, situados em Brasília, Ceilândia e Samambaia. Para o atendimento de pessoas com transtorno mental (tm) são sete CAPS, seis na modalidade II, localizados nas regiões administrativas de Brasília, Paranoá, Planaltina, Taguatinga e Riacho Fundo; o último inaugurado foi o de Brazlândia no dia 07/03/2018, e sendo um na modalidade III, em Samambaia, Para o atendimento da população infanto juvenil, com transtorno psiquiátrico e problemas de álcool e outras drogas graves são quatro CAPSi de referência, localizados nas cidades de Brasília, Recanto das Emas, Sobradinho e Taguatinga. Vários serviços CAPS dispõem de área física precária ou inadequada para desenvolvimento das atividades terapêuticas. Essa rede CAPS no DF possui cobertura média de 0,62 por 100 mil habitantes, considerada boa, segundo parâmetros do Ministério da Saúde, todavia verifica-se nas regiões de saúde sul, oeste e centro sul uma cobertura baixa, com parâmetros entre 0,20 e 0,34 ${ }^{18}$. Da mesma forma, as equipes Núcleo de Apoio a Família encontramse com número reduzido para todo o DF.

As pessoas com complicações pelo uso de álcool e outras drogas, agravamentos clínicos ou que necessitam de desintoxicação moderada ou grave são direcionadas para as emergências e 
leitos de referência nos hospitais gerais mais próximos da residência. Desintoxicações leves e moderadas também são feitas no CAPSad III. Convênios e credenciamento também são firmados entre a SES/DF e as comunidades terapêuticas para ocupação de leitos. Outra ação estratégica de intervenção para usuários de álcool e outras drogas em situação de rua são realizadas pelas equipes dos Consultórios na Rua. Têm uma ação articulada a outros setores como a assistência social, as Unidades de acolhimento para atenção à população em situação de vulnerabilidade social e os Centros de Atenção à População de Rua.

Quanto ao acesso, há transporte público que serve todos os locais, mas como os territórios de abrangência dos CAPS são amplos, parte dos usuários têm dificuldade de deslocamento. Quanto às equipes de saúde mental que atuam nos CAPS e as práticas profissionais serão descritas à frente.

A dimensão trabalho fica premente na organização da vida dos usuários da saúde mental em função dos prejuízos decorrentes do adoecimento psíquico, o que provoca a necessidade de discussão da concepção de reabilitação psicossocial, como fator de autonomia, inclusão social e cidadania. Nessa perspectiva, o trabalho no campo da saúde mental requer estabelecer uma rede de suporte comunitário e interssetorial: saúde, trabalho e emprego, educação, assistência social e arte e cultura.

Inspirados nos princípios de economia solidária, cooperativismo social e associativismo ${ }^{19}$, os CAPS investigados no DF têm desenvolvido iniciativas de geração de trabalho e renda, mas de forma mais empíricas e frágeis, pois os profissionais referem ter dificuldade de apoio financeiro para a sustentabilidade, ou mesmo, de tempo dada a insuficiência numérica profissional para as devidas articulações comunitárias ou de pessoal para maior profissionalização delas. Alguma sobra financeira é distribuída para manutenção das oficinas e a outra entre os usuários envolvidos.

As iniciativas de geração de renda são diversas, a exemplo da produção de artesanato, mosaico, bazar, customização, ecolavagem para automotivos, horta comunitária, grupo de música, coral, culinária e outras. Para incrementar a comercialização da produção feita em algumas dessas oficinas de vários CAPS, há uma banca na Feira da Torre, espaço turístico importante em Brasília, com a participação de usuários artesãos e profissionais.

Bürke e Bianchessi ${ }^{20}$ discutem a importância trabalho com vistas à inclusão social dos usuários da saúde mental. Além da necessidade de valor social, tem-se que o modo de produção capitalista exige cada vez mais profissionais competitivos e qualificados, o que assume um caráter potencialmente excludente para um grande contingente da população com problemas mentais, e que, na sua maioria, se apresentam mais vulneráveis às condições sociais. Além disso, a maioria dos portadores de transtorno mental tem direito e recebem o benefício, fato que impede de serem devidamente registrados segundo as leis vigentes.

Neste sentido, a gestão local tem trazido na pauta política a necessidade de fortalecer a estratégia 
do trabalho como fator de inclusão social dos usuários no Distrito Federal, apoiada em princípios da economia solidária, do trabalho e cooperativismo e da geração de renda ${ }^{18,21}$. O Observatório de saúde mental, da Universidade de Brasília, localizado no Núcleo de Estudos de Saúde Pública, tem realizado desde 2017, um movimento de sensibilização e articulação dos CAPS para problematização da importância do trabalho como fator de produção de sentidos e de inclusão social, com iniciativas de ofertar ações interventivas de processos formativos e participativos, com o envolvimento dos segmentos de profissionais, usuários e familiares e de outros setores apoiados nos princípios da economia solidária e do tratamento comunitário ${ }^{22}$.

\section{2 - Caracterização socioprofissional dos profissionais de saúde que atuam nos CAPS}

Para que se possa compreender a organização interna e os processos de trabalho dos CAPS é apresentado o perfil dos profissionais, considerando a categoria profissional.

Vale ressaltar que, dos 159 profissionais, lotados nos CAPS, aproximadamente $80 \%$ participaram da pesquisa, o que permite inferir que os resultados apresentados expressam de maneira significativa a realidade. Essa representatividade não diz respeito somente ao quantitativo de respondentes, mas também à diversidade de categorias profissionais que participaram do estudo. Em relação a esse recorte, proporcionalmente, foi entrevistada a mesma quantidade de profissionais, o que reforça a credibilidade quanto ao retrato da realidade do Distrito Federal.

Nos CAPS do DF, há uma diversificação profissional com participação de assistentes sociais, enfermeiros, médicos, psicólogos, técnicos de enfermagem e terapeutas ocupacionais. Há também profissionais cujos cargos não estão ligados diretamente à assistência, porém participam de atividades assistenciais, a exemplo de alguns técnicos administrativos (Gráfico 1).

Gráfico 1 - Distribuição dos 159 profissionais dos 9 CAPS, participantes da pesquisa, por categoria profissional de nível superior e médio. 2012, Distrito Federal.

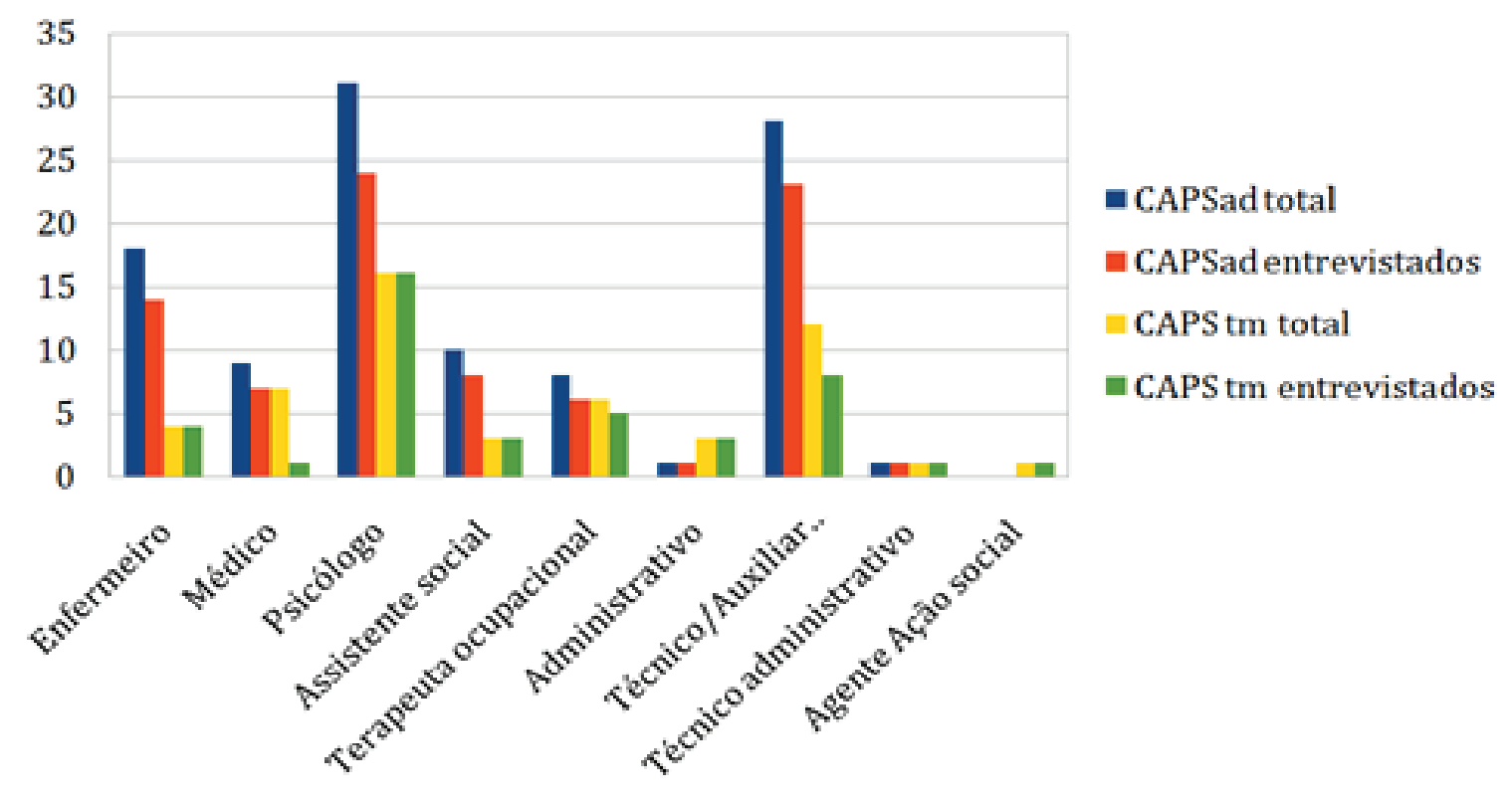

ISSN 1982-8829 Tempus, actas de saúde colet, Brasília, 11(4), 197-220, dez, 2017. Epub Ago/2018 
Gênero e idade são variáveis que também conformam a organização dos serviços investigados. Elas tendem a reproduzir no trabalho as relações experimentadas e vivenciadas no sistema social em que estão inseridas.

Dentre os profissionais entrevistados, há predominância significativa de mulheres, tanto para as categorias de nível superior $(88 \%)$, como para as de nível médio $(83,6 \%)$, propiciando a reflexão no sentido de que as profissões designadas ao cuidado ainda são predominantemente compostas por mulheres, como, também, as representações decorrentes da construção histórica dos comportamentos classificados hoje como transtorno mental estão ancoradas ao cuidado exercido pelas mulheres, desde os primórdios da humanidade.

Observa-se que a maioria dos trabalhadores são pessoas adultas jovens, tanto no nível superior quanto no médio, embora os profissionais de nível médio estejam na faixa etária um pouco mais elevada (Gráfico 2).

Na SES DF, a composição das equipes é mediante concurso público geral para qualquer área da saúde, exceto a categoria médica, que é por especialidade. A lotação é de livre escolha desde que tenha vaga disponível.

Gráfico 2 - Distribuição dos profissionais entrevistados de nível superior e médio, dos CAPS, segundo idade. 2012, Distrito Federal.

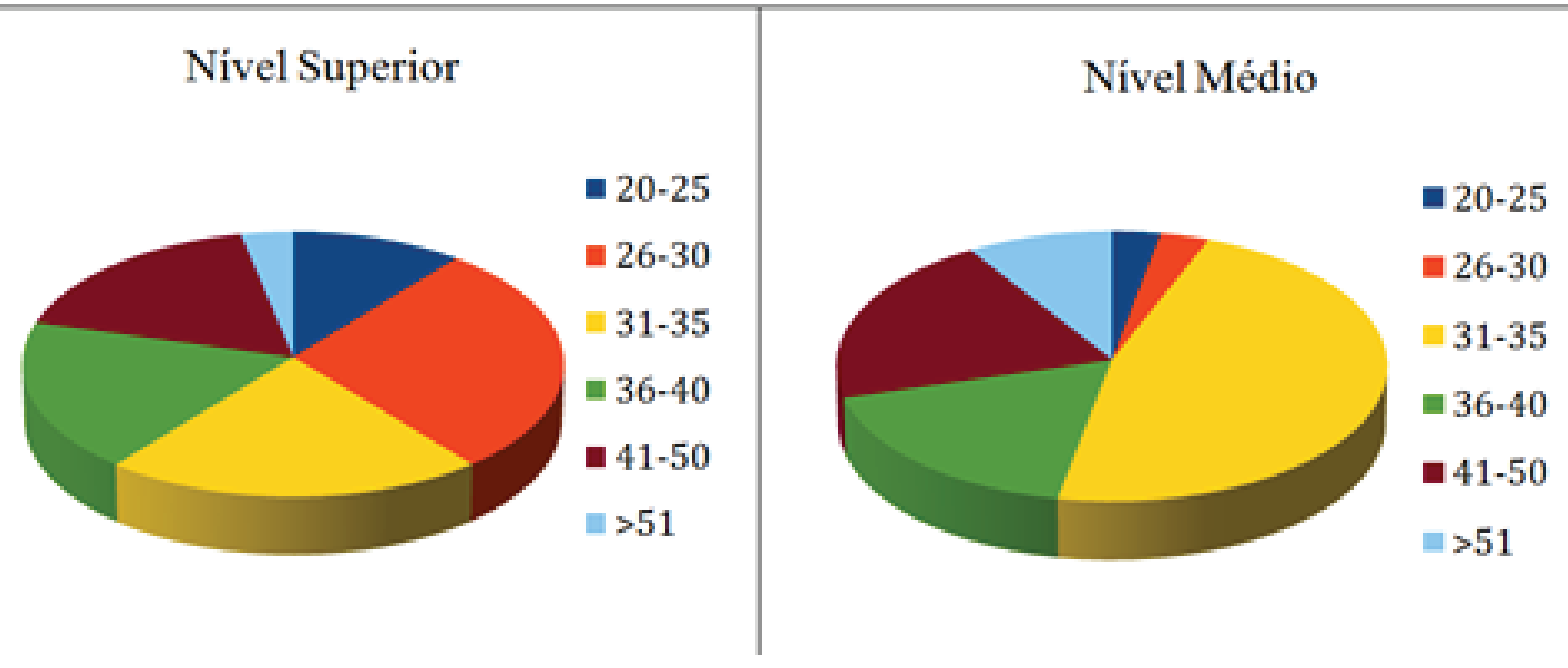

O tempo de formado somado à busca e oportunidade de capacitação são variáveis que influenciam sobremaneira a organização dos processos de trabalho, uma vez que vêm carregadas de referenciais mobilizadores de reflexão, portanto são potenciais provocadores de transformação. Observa-se no Gráfico 3, dentre os trabalhadores de nível superior que a maioria possui até dez anos de formado, ou seja, são pessoas com uma trajetória profissional recente. Na contrapartida, pouco mais de $60 \%$ dos trabalhadores de nível médio possuem mais de dez anos de conclusão de nível técnico, configurando profissionais com mais tempo de experiência. Pressupõe-se que esse tempo requer um olhar diferenciado quanto aos conhecimentos e habilidades exigidos no campo da saúde mental, 
com vista a concretizar uma assistência cujo paradigma é regido pelos princípios da abordagem psicossocial.

O paradigma psicossocial, como orientador da formação e atuação dos profissionais de saúde mental, exige que aspectos teóricos e práticos sejam vivenciados para a composição de competências e habilidades requeridas para essa forma de organizar o cuidado em saúde.

$\mathrm{Na}$ avaliação dos profissionais sobre receber uma adequada formação durante o ensino de graduação ou técnico, a grande maioria considerou que ela deixou a desejar, avaliando-a como deficiente ou parcialmente deficiente, e que foi desenvolvida no cotidiano do trabalho.

Evidencia-se também o interesse dos profissionais em prosseguir com cursos de qualificação em âmbito da pós-graduação strictu sensu e latu sensu, e na realização de cursos de curta duração, conforme Gráfico 3.

Gráfico 3- Percentual dos profissionais entrevistados nos CAPS do DF, de nível superior e médio, quanto ao tempo de formação profissional. 2012, Distrito Federal.

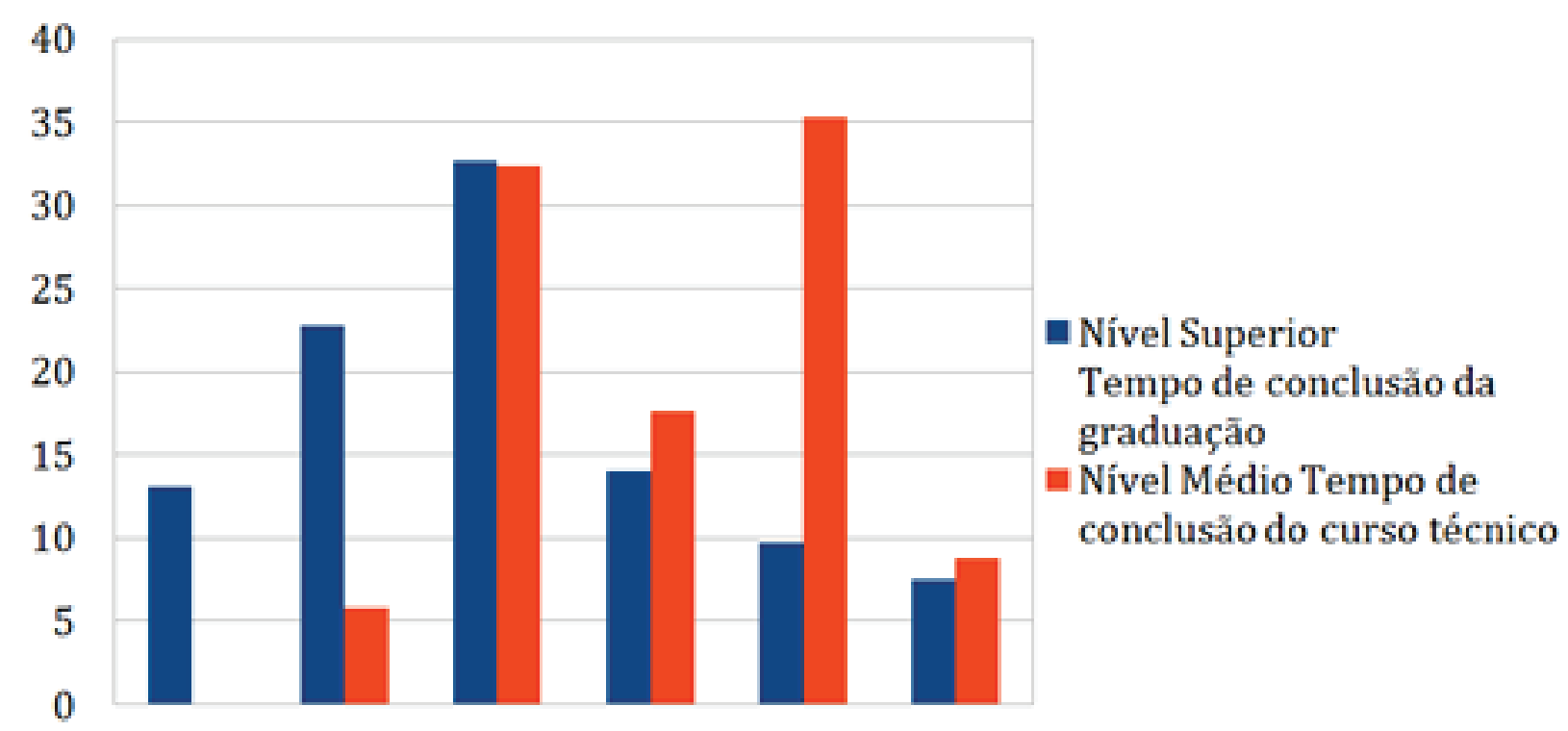

Até $2 \quad 3$ a $5 \quad 6$ a $10 \quad 11$ a 1516 a 2526 mais anos

No Gráfico 4, ressalta-se dentre os profissionais de nível superior, o significativo número dos que têm pós graduação (47,8\%), sendo mais frequente especialização em diferentes modalidades, boa parte na área de saúde mental, vários com mestrado e alguns com doutorado. Os que declararam ter realizado curso de especialização em saúde mental, relataram que a abordagem teórica foi prevalente, mas que também tiveram a abordagem de estudos de casos e poucos referiram a abordagem assistencial. Estes indicadores remetem à reflexão da carência de capacitação voltada para as experiências concretas que dão a performance no mundo do trabalho.

Em relação aos profissionais de nível médio, vários possuem curso de graduação concluído 
(cerca de 47\%) ou em andamento, nas áreas de Enfermagem, Serviço Social, Educação Física, Administração, Direito, Pedagogia, dentre outras. Os que têm graduação em outras áreas manifestaram interesse em se manter vinculados ao campo da saúde. Nesse grupo, verificou-se ainda que alguns haviam feito ou se encontravam fazendo especialização.

Revelou-se também significativa a participação em curso de atualização. Os temas mais ilustrados para os cursos de curta duração realizados foram principalmente em saúde mental, drogas e dependência química, acolhimento, saúde da família, promoção da saúde, prevenção de DST e HIV, adolescência, direitos humanos, sexualidade e gestão em saúde.

Embora pareça ter um campo fértil entre os profissionais com conhecimento propício para integrar a teoria à prática no cotidiano do trabalho, com foco no paradigma psicossocial, paradoxalmente, os profissionais relatam dificuldades para aplicação desse conhecimento como um elemento agregador no trabalho conjunto dos profissionais, dada a pouca experiência na graduação junto a essa população específica com transtorno mentais e/ou com uso de álcool e outras drogas, ou quando esta ocorreu durante a formação ou em experiência de trabalho, a lógica instituída hegemonicamente era no modelo manicomial.

Gráfico 4 - Distribuição dos profissionais dos CAPS de nível superior e médio, quanto à sua qualificação para o trabalho. 2012, Distrito Federal.

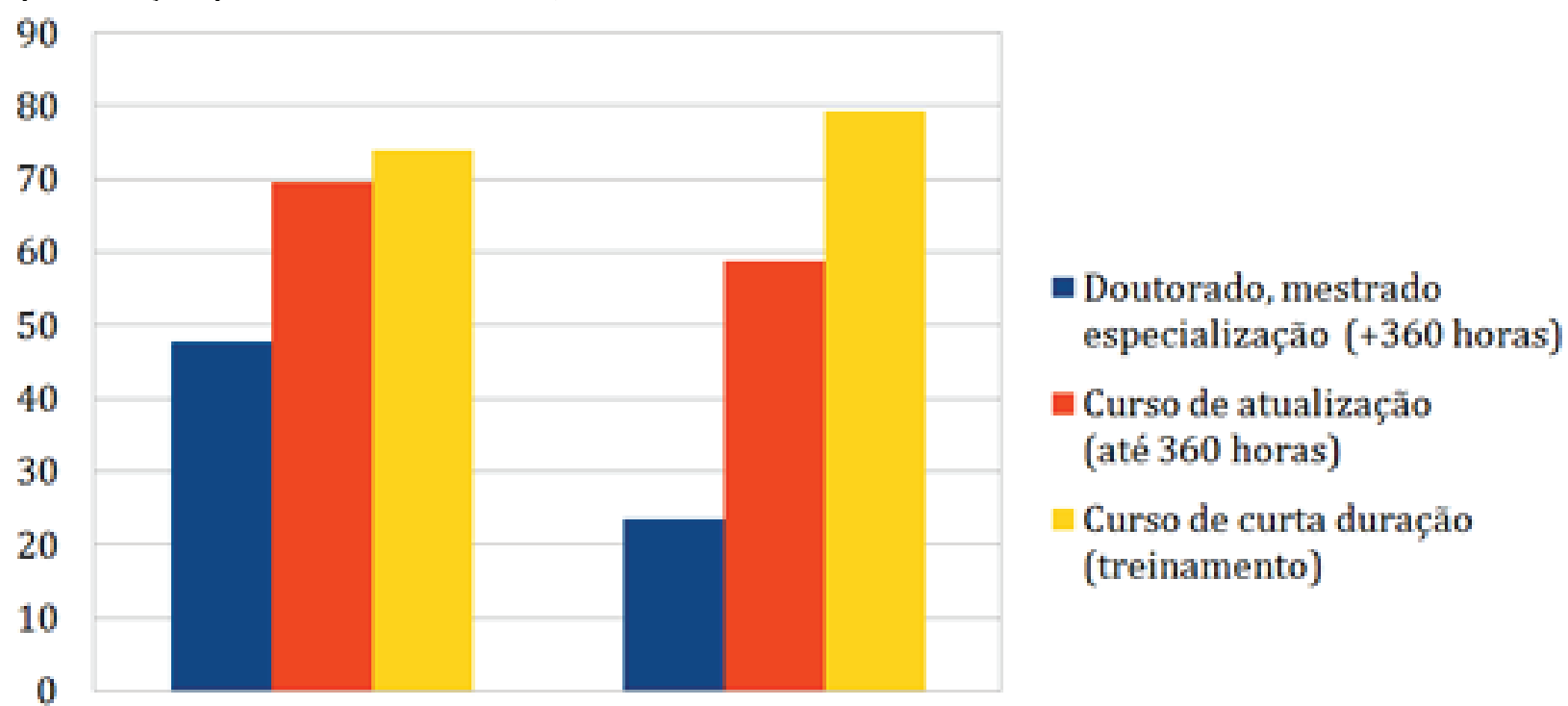

Nível Superior

Nível Médio

Acrescentam ainda, a necessidade de políticas públicas específicas para a formação de recursos humanos para atuar nas RAPS, seja por oferta de residências multiprofissionais, de pós-graduações latu sensu e strictu sensu, ou outra modalidade de qualificação dos processos de gestão e intervenção em saúde mental, à exemplo da supervisão clínico institucional, um dispositivo que pode promover o movimento para mudanças na abordagem psicossocial junto à 
equipe, serviços e trabalhadores no campo da saúde mental ${ }^{23}$.

A supervisão clínico-institucional trata-se de um programa de qualificação dos serviços CAPS, com previsão de incentivo financeiro, e encontra-se definida na Portaria $N^{\mathbf{0}} \mathbf{1 . 1 7 4}$, de 07 de julho de $2005^{24}$,

"o trabalho de um profissional de saúde mental externo ao quadro de profissionais dos CAPS, com
comprovada habilitação teórica e prática, que trabalhará junto à equipe do serviço durante pelo menos
3 a 4 horas por semana, no sentido de assessorar, discutir e acompanhar o trabalho realizado pela
equipe, o projeto terapêutico do serviço, os projetos terapêuticos individuais dos usuários, as questões
institucionais e de gestão do CAPS e outras questões relevantes para a qualidade da atenção realizada"24.

É importante avaliar a necessidade de reforçar processos de educação permanente para os princípios das práticas que estimulem um novo lugar para o portador de sofrimento psíquico, pautado na subjetividade, cidadania e direitos humanos. A formação de conhecimento no campo da saúde deve apostar em profissionais mais autônomos e competentes de forma a serem sujeitos técnicos e políticos na implantação de gestão e práticas de cuidado que irão consolidar a abordagem psicossocial no cotidiano dos serviços - atenção integral aos usuários, gestão para o trabalho em equipe e a oferta de atividades em consonância com as diretrizes das políticas nacionais para a atenção à saúde mental no SUS/DF.

Verificou-se que a maioria dos profissionais que atuam nos CAPSad e CAPStm tem experiência profissional de até três anos na área da saúde mental. Este panorama evidencia que os CAPS do DF são um dispositivo recente, diferenciado dos serviços especializados tradicionais em saúde mental, assim pode ser um espaço privilegiado para criar e reinventar arranjos de trabalho e práticas de cuidado que possam dar sentido e valores ao trabalho na abordagem psicossocial.

Os profissionais de nível superior que revelam ter o segundo emprego é significativo $(58,7 \%)$, sendo que para os profissionais de nível médio esse indicador se mostra menor (26,5\%), possivelmente por ter jornada de trabalho prevalente de 40 horas. Embora o salário seja maior em relação à média nacional, eles atribuem o fato de ter mais de um vínculo trabalhista à necessidade de melhorar a qualidade de vida. Cabe ressaltar que é permitido aos profissionais da área de saúde acumular dois empregos desde que respeitada a carga horária total de 60 horas semanais. Assim, um mesmo trabalhador pode ter duas matrículas na Secretaria de Saúde do DF ou acumular com outra instituição, o que não é raro de se encontrar principalmente nos profissionais de nível superior. As configurações do tempo de trabalho quanto a duração, distribuição/flexibilidade e intensidade tem acompanhado as transformações no mundo do trabalho a partir da década de 80 e 90 e cada vez mais presente no cotidiano dos trabalhadores, e estudos apontam que "a elevação da intensidade do tempo de trabalho está diretamente relacionada ao crescimento das manifestações de adoecimento físico, psíquico e emocional dos trabalhadores" ${ }^{25}$. 
Entre os profissionais entrevistados de nível superior, quase a metade relatou ter ocupado cargo de gerência em alguma unidade de saúde mental. Poucos trabalhadores de nível médio informaram que já ocuparam referido cargo, tendo sido por pouco tempo, em torno de um ano, alguns técnicos de enfermagem relataram que muitos dos cargos de gerência ocupados ocorreram em clínicas particulares.

\section{3 - A organização do trabalho e as práticas de cuidado, realizadas pelos profissionais nos} CAPS quanto à adequação à Política Nacional de Saúde Mental

Os profissionais de modo geral destacam a importância dos CAPS como dispositivos estratégicos para mudança de paradigma da abordagem tradicional, centrado no saber da psiquiatria, para a abordagem psicossocial. No que se refere ao alinhamento do serviço com a política nacional de saúde mental, responderam de forma prevalente que seguem parcialmente ou não seguem.

As principais dificuldades apontadas pelos profissionais passam por dimensões relacionadas aos profissionais e aos limites institucionais, de ordem políticas, financeiras, recursos humanos, materiais ou de infraestrutura. Essas duas últimas dificuldades são percebidas de forma mais acentuadas em serviços CAPS com menor tempo de criação, que ainda estão em fase de implantação.

Em relação aos limites dos profissionais citam como dificuldade o pouco preparo técnicoassistencial, a motivação e o interesse diferenciado para o trabalho em saúde mental dentre os integrantes da própria equipe trabalho. Eles identificam que há profissionais que se dedicam em avançar na organização do trabalho e das práticas de saúde na lógica psicossocial, contudo tem outro grupo de trabalhadores que participa, mas pouco se dedica para fazer o trabalho de forma engajada e responsabilidade compartilhada.

Uma estratégia adotada em todos os CAPS que os profissionais reconhecem favorecer a comunicação interpessoal, ajustes no processo de trabalho e pactuação para o trabalho da equipe é o dispositivo de reunião de equipe, que ocorre semanalmente, com a participação de todos os profissionais de saúde. Assim, na avaliação da adequação das relações de equipe de trabalho, reconhecem que estão aprendendo a sentar em roda, compartilhar e respeitar saberes de diferentes áreas profissionais, que é um processo contínuo e nada fácil, envolver todos para integrar e usar esse espaço positivamente para processos pedagógicos e de organização do trabalho.

Os profissionais admitem que sentar em roda permite avanços para experimentar maior horizontalidade nas relações de trabalho e práticas mais afinadas com a política nacional e local. Eles ressaltam que buscam, na organização do trabalho em equipe, atuar mais na lógica da integração, esforçando-se para a articulação das ações e interações dos agentes, conforme modelo organizativo, apresentado por Peduzzi ${ }^{26}$. 
Quanto à avaliação sobre a adequação dos CAPS em cumprir às diretrizes políticas nacionais de atenção à saúde mental, mais da metade dos profissionais de saúde afirmaram que ocorre parcialmente, pois são muitos os limites institucionais que fogem à governabilidade dos profissionais, o que acaba por sobrecarregar a organicidade do trabalho nos CAPS, comprometendo o acesso e a integralidade da atenção aos usuários da saúde mental.

Assim, eles destacam entre os limites institucionais que consideram externos a eles, a insuficiência numérica de CAPS e de outros dispositivos de cuidado da malha da Rede de atenção psicossocial; a baixa articulação dos pontos da Rede de atenção psicossocial: rede hospitalar, atenção básica, serviços de urgências e emergências e dispositivos de reabilitação; da insuficiência do quantitativo de profissionais de saúde, condições de trabalho inadequadas, baixa valorização da gestão em priorizar a atenção à saúde mental na agenda política local, mesmo com os esforços da coordenação de saúde mental para avanços da RAPS no Distrito Federal.

Foi possível observar nos serviços, bem como, nos relatos dos profissionais uma congruência das informações sobre as práticas de cuidado desenvolvidas nos CAPS, de maneira a afinar e atender as recomendações da Portaria $\mathrm{N}^{\mathrm{o}} 336 / \mathrm{GM}^{7}$. Assim, verifica-se uma oferta variada de atendimentos e acompanhamentos individuais e grupais. A modalidade em grupo é priorizada na oferta de diferentes oficinas terapêuticas: expressivas, educativas, motoras, ioga, crochê, caminhada, horta, jornal, arte em papel, bordado, mosaico, capoeira, terapia corporal, grupos de convivência, e atividades comunitárias como eventos comemorativos e festivos, assembleias entre outras. Estas podem ser modificadas a depender dos usuários e do corpo técnico da instituição. Acompanhamentos individuais psicoterápicos e em grupos para os pacientes e familiares.

Evidencia-se na organização do trabalho dos profissionais dos CAPS que, apesar da diversidade de atividades em grupo, ainda concebem de forma expressiva a realização de intervenções individuais, conforme apontado. Esse gráfico retrata minimamente dois ângulos que podem ser compreendidos de formas distintas. Se, por um lado, pode dar a entender que o foco continua em atividades individuais, por outro ele pode representar um salto significativo na reorganização do conjunto das atividades. Sem deixar de ter foco no individual, são apresentadas atividades coletivas como parte da assistência prestada nos CAPS. 
Gráfico 5 - Percentual das atividades individuais e em grupo realizadas pelos profissionais de nível superior e médio dos CAPS do DF. 2012. Distrito Federal.

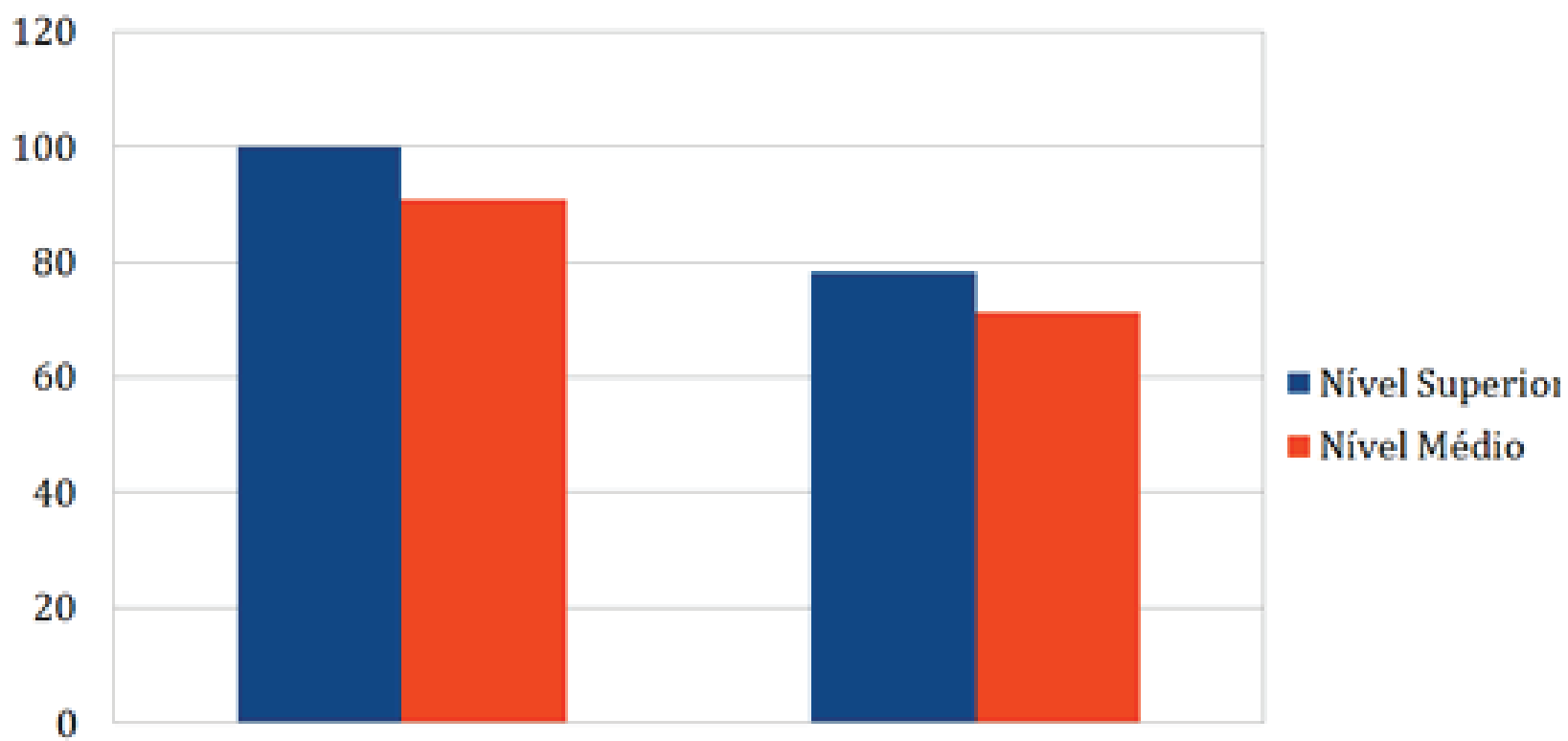

Individual

Grupo

Costa Rosa afirma que a abordagem psicossocial requer que os profissionais possam problematizar a dimensão político-ideológica e éticas desse modelo de saúde e das práticas desenvolvidas na atuação terapêutica, para uma imprescindível redefinição do objeto e dos meios de trabalho, na organização do trabalho multiprofissional, de forma a romper com a lógica da divisão técnica do trabalho no modelo vertical uniprofissionalmente, centradas e fragmentadas (modo asilar) para avançar em modelos horizontais de maneira a "favorecer concepções do objeto centradas no saber múltiplo, ... e para relações terapêuticas em que se exercitam práticas de intersubjetividade horizontal, bases para a singularização"”.

Os profissionais citaram a participação na elaboração do Projeto Terapêutico Singular, com alguns referindo arranjos locais de designação de técnico de referência junto a um conjunto de usuários, onde geralmente em reuniões da equipe buscam discutir aqueles casos mais complexos.

As atividades de acolhimento foram citadas, todavia, prioritariamente com agendamento programado segundo a organização de cada serviço, justificado pela grande demanda e abrangência do território, com demanda represada, e vários CAPS citaram ter lista de espera que poderia ser de semanas ou até meses para o usuário ter o acesso ao serviço.

De modo geral, poucos profissionais referiram haver uma fluidez para realizar o matriciamento e promover a integração com a atenção básica e articulação em rede dos recursos sociais e comunitários. As atividades de visita domiciliar, busca ativa e eventos comunitários ainda tem frágil organização na fala do conjunto dos profissionais. Dentre os fatores mais citados que dificultam a aproximação e o diálogo, mais especificamente com a atenção básica, estão a insuficiência de quadro de pessoal, a falta de transporte e, a sobrecarga da demanda no próprio serviço.

Tempus, actas de saúde colet, Brasília, 11(4), 197-220, dez, 2017. Epub Ago/2018 ISSN 1982-8829 


\section{$213 / /$}

Entre as diretrizes atribuídas ao CAPS, é esperado que ele seja o ordenador da atenção nos territórios de atuação seria o responsável por buscar estratégias de integração entre a saúde mental e a atenção básica. É uma diretriz prioritária na política de atenção a saúde mental e pode ser fortalecida pelo dispositivo do apoio matricial, com vistas a reduzir a demanda por serviços especializados, na medida em que possam ampliar competências para o cuidado em saúde mental e na definição de responsabilidades, de forma compartilhada, principalmente na abordagem da falta de sistemas estabelecidos de saúde mental em diversos países e localidades ${ }^{27}$.

\footnotetext{
“o apoio matricial como um arranjo organizacional de suporte técnico aos serviços de atenção básica e a principal estratégia de qualificação da ESF para atender às demandas de saúde mental da população. Uma equipe técnica responsável pelo apoio matricial compartilha casos com equipes de saúde da família, por meio de discussões conjuntas de casos, intervenções conjuntas junto às famílias e comunidades ou atendimentos compartilhados" 27.
}

Essa fragilidade da integração dos CAPS com a Atenção Básica suscita uma reflexão importante dimensão da abordagem psicossocial se efetivar no território. Dessa maneira, cabe problematizar sobre o quanto os profissionais dos CAPS tem considerado as questões macro institucionais como determinantes e limitantes para o desenvolvimento do cuidado ampliado, se restringindo a um papel técnico assistencial de prover cuidados de saúde no espaço institucional, se desobrigando como atores políticos em buscar articulações para o acesso integral a saúde e a cidadania dessa clientela e as suas implicações.

Neste sentido, os CAPS que teriam por função reiterar o tratamento em liberdade e a valorização da cidadania, podem não se ater "para os riscos da institucionalização ou as novas cronicidades nos espaços do CAPS que podem reforçar uma relação de dependência dos usuários em relação a esses serviços" ${ }^{28}$.

A participação dos familiares é uma importante diretriz no tratamento, reabilitação psicossocial e inclusão social dos usuários com transtornos mentais e com problemas relacionados ao uso de álcool e outras drogas. Para tanto, a família precisa ser considerada como o principal dispositivo de apoio no cuidado da pessoa e na relação com a sociedade para processos de ressignificação da loucura, dos preconceitos e estigmas associados. A família é precisa ser considerada

uma aliada, uma parceira no processo de reabilitação psicossocial do usuário. A atenção psicossocial, associada ao protagonismo das famílias, vai facilitar a reinserção social do usuário e a promoção da saúde do núcleo familiar, considerando as dimensões pessoais, biológicas, sociais e políticas que envolvem o cotidiano da vida ${ }^{29}$.

Quando indagados se realizam atendimento familiar, a maioria afirma que "atende familiares", grande parte das vezes em conjunto com outro profissional, caminhando para uma prática que indica corresponsabilização entre os membros da equipe. Entretanto, pode ser ampliada, já que 
alguns profissionais relataram não fazer nenhum tipo de atendimento aos familiares.

Quanto à abordagem utilizada no atendimento à família, a predominante é a sistêmica. Outras abordagens citadas principalmente pelos psicólogos e em menor escala alguns psiquiatras, foram cognitiva, psicanalítica, pichoniana, gestalt, comportamental, cognitivo-comportamental, psicoeducação e os referenciais de autoajuda e acolhimento foram mais referidas mais comumente pelas outras categorias profissionais de nível superior.

O documento "Saúde mental no SUS: os Centros de Atenção Psicossocial” reforçam que os serviços da atenção psicossocial façam investimentos no cuidado à família, por meio de atendimento nuclear e a grupo de familiares, atendimento individualizado, visitas domiciliares, atividades de ensino e de lazer, potencialização das ações comunitárias, buscando a integração do serviço e dos usuários, na perspectiva da participação e organização social, com a família, a comunidade e a sociedade como um todo ${ }^{30}$.

No que tange à organização associativa extra CAPS das famílias, cabe registrar a presença no DF do movimento social ASSIM - Associação dos amigos da saúde mental, com participação ativa na discussão das questões da saúde mental e fóruns de debate sobre os desafios da política de saúde mental. A criação de mais movimentos dessa natureza nos diferentes territórios pode ser apoiada inicialmente pelos profissionais de saúde mental nas práticas de intervenção das famílias, que devem ser entendidas em sua complexidade, com vistas ao seu empoderamento e maior reivindicação para respeito aos princípios de cidadania e dos direitos humanos.

Ao perguntar aos profissionais se fazem preparo para a alta ao longo do tratamento e se promovem ações visando à autonomia, têm-se respostas aparentemente contraditórias, pois, enquanto a maioria afirma que promove ações para a autonomia dos usuários ao longo da permanência dos mesmos no CAPS, um número significativo afirma não realizar o preparo para a alta no mesmo tempo. Ou seja, não há a compreensão que ações para a autonomia sejam preparatórias para a alta.

O não estabelecimento dessa relação instiga a pensar se as ações para a autonomia efetivamente caminham para alcançar essa meta de modo que a alta seja uma consequência natural desse processo. Também se depreende que a alta é vista como uma ação pontual e não como o resultado de um processo no qual são oferecidas aos usuários condições de desenvolvimento de habilidades que lhes permitam participar de forma ativa da vida em sociedade ${ }^{31}$.

A autonomia entendida como a produção de subjetividades, seja nas relações entre profissionais de saúde e usuários, e destes com outros pontos da malha da rede social, é um processo de construção em que se busca a participação protagonista na produção de sentidos no desenvolvimento das práticas institucionais dos serviços substitutivos. Assim, a abordagem psicossocial além de problematizar as relações históricas desenvolvidas nas instituições asilares 


\section{$215 / /$}

manicomiais, de segregação e de exclusão, oferece subsídios que apontam para outra forma de produzir saúde.

Os profissionais se percebem atores institucionais importantes para operar mudanças e dar concretude a própria concepção técnica-assistencial e ideológica do dispositivo dos CAPS do modelo psicossocial, mas não estão livres de conflitos de naturezas diversas para instituir hegemonicamente o tratamento na perspectiva comunitária, que perpassam pela formação heterogênea dos profissionais, à lógica das especialidades no trabalho em saúde mental, e a centralidade do cuidado nas necessidades dos usuários; além dos limites institucionais já citados. Mas a estratégia de trazer essas questões para a discussão na organização do trabalho em equipe tem permitido avançar em saberes e práticas de cuidado em maior consonância com o modelo psicossocial e, consequentemente, com as diretrizes políticas nacionais de atenção à saúde mental.

Os CAPS são considerados dispositivos recentes no DF, seus profissionais de saúde estão na construção de um processo de trabalho diferente da abordagem tradicional, adotando a liberdade, a autonomia e a cidadania dos usuários como aspectos norteadores do processo de trabalho. Daí cabe trazer para discussão das equipes de saúde dos CAPS a finalidade do trabalho terapêutico em um processo de desinstitucionalização.

\section{CONSIDERAÇÕES FINAIS}

Os resultados exploratórios deste estudo permitem ter uma compreensão das estratégias e práticas de cuidados que tem conformado o trabalho dos profissionais de saúde nos Centros de Atenção Psicossocial- CAPS, e os desafios enfrentados por eles para adequação ao modelo psicossocial preconizado pela Política de atenção à saúde mental.

Os profissionais evidenciam o esforço realizado por eles para dar concretude no cotidiano da organização do trabalho para instituir o modelo psicossocial nas relações interpessoais para a construção do trabalho em equipe, a busca de melhor preparo técnico assistencial dos profissionais e a relação de cuidado com o usuário da saúde mental com ênfase na autonomia, na participação e cidadania. Contudo, os profissionais afirmam que os avanços só não são maiores devido às precárias condições prediais, materiais e econômicas dos CAPS e aos limites macroestruturais para melhor adequação e cumprimento das diretrizes Políticas Nacionais para a atenção integral à saúde mental, pois remetem a necessidade de criação e expansão dos equipamentos de saúde para a conformação dos pontos da rede de atenção psicossocial para cobertura das regiões de saúde, que estão no bojo dos problemas e embate político de afirmar o SUS para ampliação do acesso e a integralidade da atenção a saúde no conjunto das políticas sociais.

Verifica-se a necessidade de investimento em relação à capacitação e preparo profissional para atuar no campo da saúde mental, de modo geral, os profissionais de saúde mental dos CAPS relatam um preparo deficiente na formação, muitas vezes ocorrido de forma empírica na prática cotidiana 
do trabalho, o que remete à necessidade de investimentos em educação permanente.

Todavia, a despeito dos limites institucionais e profissionais, os CAPS são reconhecidos e valorizados pelos profissionais de modo geral, como dispositivo diferencial, potente e substitutivo ao modo asilar. Os profissionais, ao avaliarem globalmente as práticas profissionais, no somatório das ações realizadas nos serviços, destacam a importância dos CAPS no atendimento às necessidades dos usuários e familiares para uma atenção integral em saúde mental, mas encontram limites para fazer a articulação em rede com outros setores e com a comunidade.

Os profissionais se percebem em um processo de construção contínuo e progressivo de aprendizagem e de ressignificação do modelo asilar hospitalocêntrico para a conformação do modelo psicossocial, ao possibilitarem uma aquisição de saberes e práticas que os permitem afirmar o CAPS como um novo espaço de cuidado para os usuários da saúde mental ao buscar instituir produções de cuidado com ênfase nos valores de liberdade e cidadania dos usuários.

Assim, percebe-se que nas práticas institucionais, desenvolvidas pelos profissionais nos CAPS, tem fortalezas e fragilidades que se encontram em fase de transição e de formação de identidade para novos saberes, práticas e valores nas relações sociais para se avançar à caracterização objetiva do modelo modo psicossocial como instituído hegemonicamente

Os achados evidenciam aspectos sobre o papel dos profissionais de saúde na organização da atenção a saúde mental no Distrito Federal, como também suscita a necessidade o melhor delineamento de estratégias no âmbito da gestão e da organização do trabalho em saúde mental para progredir na qualificação da atenção psicossocial, mas cabe considerar a realização de mais estudos visando maior monitoramento do sistema de gestão, dos indicadores de saúde mental, dos recursos financeiros aplicados, do acesso e efetividade da rede e outras variáveis envolvidas para a atenção integral aos usuários da saúde mental.

\section{REFERÊNCIAS BIBLIOGRÁFICAS}

[1] Costa-Rosa, A. O modo psicossocial: um paradigma das práticas substitutivas ao modo asilar. In: AMARANTE, P., org. Ensaios: subjetividade, saúde mental, sociedade [online]. Rio de Janeiro: Editora FIOCRUZ, 2000. Loucura \& Civilização collection, pp. 141-168. ISBN 978-857541-319-7. Available from SciELO Books Acesso em 29/03/2018

[2] Barros, Denise Dias. Cidadania versus periculosidade social, a desistitucionalização como construção do saber, in Amarante, Paulo (org.) Psiquiatria Social e reforma Psiquiatrica. Rio de Janeiro, Editora Fiocruz, 1994, 202 p. (p.171-196)

[3] Rotelli, Franco; Leonardis, Ota; Mauri, Diana. Desisntitucionalização, uma outra via. In: Nicácio, Fernanda (org). Desinstitucionalização. São Paulo, Hucitec, 1990,. p. 17- 59. p. 112

[4] Rotelli, Franco, Leonardis, Ota, Mauri, Diana. A instituiçao inventada. In: NICÁCIO, Fernanda (org). Desinstitucionalização. São Paulo, Hucitec, 1990,. P. 89- 99. p.94

[5] ORGANIZAÇÃO MUNDIAL DE SAÚDE. A saúde mental pelo prisma da saúde pública. 
Relatório sobre a saúde no mundo 2001. Saúde mental: nova concepção, nova esperança. Genebra: OPAS/OMS, p.1-16, 2001.

[6] Brasil. Lei No 10.216, de 6 de abril de 2001. Dispõe sobre a proteção e os direitos das pessoas portadoras de transtornos mentais e redireciona o modelo assistencial em saúde mental. Disponível em http://hpm.org.br/wp-content/uploads/2014/09/1ei-no-10.216-de-6-de-abrilde-2001.pdf

[7] Brasil. Ministério da Saúde. Portaria n 336, de 19 de fevereiro de 2002. Dispõe sobre a proteção e os direitos das pessoas portadoras de transtornos mentais e redireciona o modelo assistencial em saúde mental. Disponível em: http://bvsms.saude.gov.br/bvs/saudelegis/gm/2002/ prt0336_19_02_2002.html Acesso em 15/04/2018

[8] Brasil. Portaria de $n^{\circ}$ 106/2000, Cria os Serviços Residenciais Terapêuticos em Saúde Mental, no âmbito do Sistema Único de Saúde, para o atendimento ao portador de transtornos mentais. Disponível em: http://portalarquivos.saude.gov.br/images/pdf/2015/marco/10/ PORTARIA-106-11-FEVEREIRO-2000.pdf Acesso em 15/04/2018.

[9] Brasil. Lei no 10.708, de 31 de julho de 2003. Institui o auxílio-reabilitação psicossocial para pacientes acometidos de transtornos mentais egressos de internações. Disponível em: http:// www.planalto.gov.br/ccivil 03/leis/2003/L10.708.htm Acesso em 14/04/2018.

[10] Brasil. Decreto 7.508/2011. Regulamenta a Lei no 8.080, de 19 de setembro de 1990, para dispor sobre a organização do Sistema Único de Saúde - SUS, o planejamento da saúde, a assistência à saúde e a articulação interfederativa, e dá outras providências. Disponível em http:// www.planalto.gov.br/ccivil 03/ ato2011-2014/2011/decreto/d7508.htm Acesso 15/04/2018.

[11] Brasil. Portaria n 3.088/2011. Institui a Rede de Atenção Psicossocial (RAPS). http:// bvsms.saude.gov.br/bvs/saudelegis/gm/2011/prt3088_23_12_2011_rep.html

[12] Brasil. Ministério da Saúde. SAS/DAPES. Coordenação Geral de Saúde Mental, Álcool e Outras Drogas. Saúde Mental em Dados - 12, Ano 10, nº 12, outubro de 2015. Brasília, 2015. Informativo eletrônico de dados sobre a Política Nacional de Saúde Mental. 48p. Disponível em www.saude.gov.br/bvs/saudemental. Acesso em 29/03/2018.

[13] GIL, Antônio Carlos. Como Elaborar Projetos de Pesquisa. 4. ed. São Paulo: Editora Atlas, 2008. $175 \mathrm{p}$.

[14] FUREGATO, Antonia Regina Ferreira et al. Current professional practice in Brazilian mental healthcare services. Revista de Salud Pública, [S.1.], v. 14, n. 6, p. 935-945, nov. 2012. ISSN 2539-3596. Disponível em: $<$ https://revistas.unal.edu.co/index.php/revsaludpublica/article/ view/32311/42483>. Acesso em: 07/05/2018

[15] Governo do Distrito Federal, Secretaria de Estado de Saúde do DF, Subsecretaria de 
atenção à saúde, Gerencia de Saúde Mental do Distrito Federal. Plano Diretor de Saúde Mental do Distrito Federal 2011 a 2015. DISTRITO FEDERAL 2011 a 2015. Brasília, Dezembro de 2010 Disponível http://www.mpdft.mp.br/saude/images/saude_mental/Plano_Diretor_de_Saude Mental_do_DF 2011-2015_final.pdf. Acesso 29/03/2018.

[16] Lima Maria da Glória, Silva Graciette Borges da. A reforma psiquiátrica no Distrito Federal. Rev. bras. enferm. [Internet]. 2004 Oct [cited 2018 Apr 15] ; 57( 5 ): 591-595. Available from: http://www.scielo.br/scielo.php?script=sci arttext\&pid=S0034$\underline{71672004000500015 \& \operatorname{lng}=\mathrm{en}}$ http://dx.doi.org/10.1590/S0034-71672004000500015.

[17] Zgiet Jamila. Reforma psiquiátrica e os trabalhadores da saúde mental: a quem interessa mudar?. Saúde debate [Internet]. 2013 June [cited 2018 Apr 15] ; 37(97): 313323. Available from: http://www.scielo.br/scielo.php?script $=$ sci arttext\&pid=S0103$\underline{11042013000200013 \& \operatorname{lng}=\mathrm{en}}$

[18] Plano Diretor de Saúde Mental Do Distrito Federal 2017 a 2019. Governo do Distrito Federal, Secretaria de Saúde do Distrito Federal, Subsecretaria de Atenção à Saúde, Coordenação de Redes e Integração de serviços, Diretoria de Saúde Mental. 01/12/2017. Disponível em: www. saude.df.gov/images/SAIS/PDSM/__VERSAO_FINAL_APROVADA_COLEGIADO SES.pdf Acesso em 30/03/2018.

[19] Alvarez, A., Abbês Baêta Neves, C., \& Osorio da Silva, C. (2017). Saúde Mental e economia solidária: pesquisa cartográfica em um dispositivo clínico-político.Cadernos Brasileiros de Saúde Mental/Brazilian Journal of Mental Health, 9(22), 124-144. Disponível em: http://incubadora.periodicos.ufsc.br/index.php/cbsm/article/view/3379/5009 Acesso em $03 / 04 / 2018$

[19] Alvarez, A., Abbês Baêta Neves, C., \& Osorio da Silva, C. Saúde Mental e economia solidária: pesquisa cartográfica em um dispositivo clínico-político.Cadernos Brasileiros de Saúde Mental/Brazilian Journal of Mental Health, 2017, 9(22), 124-144. Recuperado de http:// incubadora.periodicos.ufsc.br/index.php/cbsm/article/view/3379 Acesso em: 09/04/2018

[20] Bürke, Kelen Patrícia, \& Bianchessi, Desirée Luzardo Cardozo. O trabalho como possibilidade de (re)inserção social do usuário de um Centro de Atenção Psicossocial na perspectiva da equipe e do usuário. Estudos e Pesquisas em Psicologia, 2013, 13(3), 957976. Recuperado em 19 de abril de 2018, de http://pepsic.bvsalud.org/scielo.php?script=sci arttext\&pid $=$ S1808-42812013000300009\&lng $=$ pt\&tlng $=$ pt

[21] Governo do Distrito Federal, Secretaria de Estado do Trabalho, Desenvolvimento Social, Mulheres, Igualdade Racial e Direitos Humanos do Distrito Federal. Plano de Ação do grupo de trabalho Saúde mental e trabalho no Distrito Federal. GDF, Brasília, agosto de 2016.

[22\} Milanese E. Tratamento comunitário: Manual de trabalho I, conceitos e práticas. São Paulo: 
Instituto Empodera; 2012

[23] Severo Ana Kalliny de Sousa, L'Abbate Solange, Campos Rosana Teresa Onocko. A supervisão clínico-institucional como dispositivo de mudanças na gestão do trabalho em saúde mental. Interface (Botucatu) [Internet]. 2014 Sep [cited 2018 Apr 08]; 18( 50 ): 545-556. Available from: http://www.scielo.br/scielo.php?script=sci arttext\&pid=S141432832014000300545\&lng=en Epub Aug 01, 2014. http://dx.doi.org/10.1590/1807$\underline{57622013.0520 .}$.

[24] Brasil. Portaria $N^{\circ} 1.174$, de 07 de julho de 2005, que destina incentivo financeiro emergencial para o Programa de Qualificação dos Centros de Atenção Psicossocial - CAPS e dá outras providências. Disponível em: http://bvsms.saude.gov.br/bvs/saudelegis/gm/2005/ prt1174_07 072005 comp.html

Acesso em 09/04/2018

[25] Cardoso, Ana Claudia Moreira. (2013). Organização e intensificação do tempo de trabalho. Sociedade e Estado, 28(2), 351-374. http://dx.doi.org/10.1590/S0102$\underline{69922013000200009}$

[26] Peduzzi Marina. Equipe multiprofissional de saúde: conceito e tipologia. Rev. Saúde Pública [Internet]. 2001 Feb [cited 2018 Apr 15]; 35( 1 ): 103-109. Available from: http://www. $\underline{\text { scielo.br/scielo.php?script=sci_arttext\&pid=S0034-89102001000100016\&lng=en. } \mathrm{http}: / / \mathrm{dx} . \text { doi. }}$ org/10.1590/S0034-89102001000100016

[27] Pande Mariana Nogueira Rangel, Amarante Paulo Duarte de Carvalho. Desafios para os Centros de Atenção Psicossocial como serviços substitutivos: a nova cronicidade em questão. Ciênc. saúde coletiva [Internet]. 2011 Apr [cited 2018 Apr 15] ; $16(4$ ): 20672076. Available from: http://www.scielo.br/scielo.php?script=sci arttext\&pid=S1413$\underline{81232011000400006 \& \operatorname{lng}=\mathrm{en}} . \underline{\mathrm{http}} \mathrm{// \textrm {dx }}$. doi.org/10.1590/S1413-81232011000400006

[28] Wenceslau Leandro David, Ortega Francisco. Saúde mental na atenção primária e Saúde Mental Global: perspectivas internacionais e cenário brasileiro. Interface (Botucatu) [Internet]. 2015 Dec [cited 2018 Apr 15]; 19( 55 ): 1121-1132. Available from: http://www.scielo.br/scielo. php? script=sci arttext\&pid=S1414-32832015000401121\&lng=en. EpubAug21, 2015. http:// dx.doi.org/10.1590/1807-57622014.1152

[29] Mielke FB, Kohlrausch E, Olschowsky A, Schneider JF. A inclusão da família na atenção psicossocial: uma reflexão. Rev. Eletr. Enf. [Internet]. 2010 out/dez; 12(4):761-5. Disponível em: http://dx.doi.org/10.5216/ree.v12i4.6812. Acesso em 20/02/2018.

[30] Brasil, Ministério da Saúde. Secretaria de Atenção à Saúde. Departamento de Ações

ISSN 1982-8829 Tempus, actas de saúde colet, Brasília, 11(4), 197-220, dez, 2017. Epub Ago/2018 
Programáticas Estratégicas. Saúde mental no SUS: os centros de atenção psicossocial / Ministério da Saúde, Secretaria de Atenção à Saúde, Departamento de Ações Programáticas Estratégicas. Brasília: Ministério da Saúde, 2004.

[31] CASTRO, Sueli Aparecida; Furegato, Antonia Regina Ferreira. Serviços de saúde e o processo de cronificação psiquiátrica. CliniCAPS, 2012 [18] 26-36.

Artigo apresentado em 10/11/2017

Artigo aprovado em 01/03/2018 Artigo publicado no sistema em 22/08/2018 